\title{
Investigation of the effect of the coating formed by microarc oxidation on the piston top on the thermal state of the internal combustion engine parts
}

\author{
Niyaz Musin ${ }^{1, *}$, and Natalia Dudareva ${ }^{1}$ \\ ${ }^{1}$ Ufa State Aviation Technical University, 12 K.Marksa st., Ufa, 450000, Russian Federation
}

\begin{abstract}
The aim of this work is to study the influence of MAO-coatings on the thermal state of the engine piston. The results of numerical modeling of the temperature distribution in the piston are presented for different values of thickness and conductivity of the coating. Regression equations are obtained. For thermal protection of the piston it is recommended to apply MAO-coatings with thermal conductivity of $0.3 \ldots 0.7 \mathrm{~W} / \mathrm{m} \cdot \mathrm{K}$ and thickness $150 \ldots 300 \mu \mathrm{m}$.
\end{abstract}

\section{Introduction}

The piston is the most loaded part of the internal combustion engine (ice). In the process, this component is exposed to pressure from gases and is heated to high temperatures $(\sim 350$ $450{ }^{\circ} \mathrm{C}$ ) [1]. As a result, the piston there is often a defect of burnout, which looks like a through hole in the bottom of the piston. Burnout usually leads to breakage of the whole engine.

The pistons are traditionally made of aluminium alloys [2, 3]. One way to reduce burnout is the use of heat-protective ceramic inserts or coatings on the top of the piston [4]. Recently, for the formation of such thermal barrier coatings on the pistons using the method of microarc oxidation (MAO) [5]. This technology allows you to create on the surface of the pistons with ceramic thermal barrier layer which consists of high-temperature oxides $[6,7]$. The MAO coating is characterized by high heat resistance (up to $2200{ }^{\circ} \mathrm{C}$ ) and good adhesion strength $[8,9]$. Coating thickness up to $400 \mu \mathrm{m}[10]$.

The use of thermal barrier coatings on the pistons of the engine requires an assessment of the impact of these coatings on the thermal state of components and the workflow engine. Studies in this area are being actively pursued by many engine research centers in the world [11-13]. However, research on the prediction of impact properties of MAO coatings on temperature of various parts of the piston, is not sufficient at present. Therefore, the goal was formulated: to investigate the effect of thickness and thermal conductivity of the ceramic coating formed on the bottom of the piston by an MAO, the thermal state of the piston.

\footnotetext{
* Corresponding author: niyaz.musin@yandex.ru
} 


\section{Research methodology}

\subsection{The object and stages of research}

The object of the study was the piston of two-stroke two-cylinder engine with a volume of $550 \mathrm{~cm}^{3}$ and a power of $37 \mathrm{~kW}$ at speed $6800 \mathrm{~min}^{-1}$. The piston has a diameter of $76 \mathrm{~mm}$ and made of hypereutectic silumin with silicon content $\sim 25-26 \%$.

The study consisted of several stages. In the first stage, the experiment was conducted for determination of coefficient of thermal conductivity of the alloy of the piston. In the second stage were numerically calculated parameters of the workflow engine in the simulation software "Albea" [14, 15]. The third phase was conducted a full two-factor numerical experiment to establish the influence of thickness and coefficient of thermal conductivity of micro-arc oxide layer formed on the bottom of the piston, the thermal state of the piston. For calculations of the third stage, we used data obtained at the first and second stages of the study.

\subsection{Determination of the thermal conductivity coefficient of the material of the piston}

The thermal conductivity coefficient of the material of the piston is determined by the formula of Wiedemann-Franz [16]:

$$
\lambda=\sigma L T
$$

where $\lambda$-coefficient of thermal conductivity of the material, $\sigma$ is electrical conductivity at temperature $T, L$ is the Lorentz number equal to $2,47 \cdot 10^{-8} \mathrm{~W} \cdot \Omega \cdot \mathrm{K}^{-2}$.

Electrical conductivity aluminum alloy of the piston were measured using the eddy current measuring specific electrical conductivity of VE-27 NC. The measurements were carried out at temperatures of $25,50,75,90{ }^{\circ} \mathrm{C}$ at least 18 times.

The value of thermal conductivity for temperatures above $90{ }^{\circ} \mathrm{C}$ were obtained by linear extrapolation.

\subsection{Numerical simulation of engine}

Numerical calculation of the examined engine in software "Albea" was carried out for maximum power, which is achieved at speed $6800 \mathrm{~min}^{-1}$. The estimated model is going in accordance with the user manual [15]. In result, data were obtained about the temperature and the pressure in the working chamber depending on the crankshaft angle. Were also obtained the values of average piston speed, temperature, pressure and volume at the beginning of the compression stroke.

\subsection{Numerical modeling of the thermal state of the piston}

Modeling of the thermal state of the piston was carried out in Ansys Mechanical. The calculated diagram indicating the boundary conditions of the third kind shown in Fig.1 [17].

Temperature field of the piston during the working cycle varies slightly and can be considered as stationary $[17,18]$. Therefore, the local values of the gas temperature and heat transfer coefficients on the surface of the combustion chamber was replaced by averaged constant temperature $\mathrm{T} 1$ and the heat transfer coefficient $\alpha_{1}$ [19]. The current averaged value of the heat transfer coefficient $\alpha$, which is necessary to calculate $\alpha_{1}$ is determined by the G. Woschni correlation [20]. 
For the calculations have been performed of three-dimensional model of the piston, consisting of two solid parts: piston of aluminum alloy and coatings of a ceramic material with different thickness.

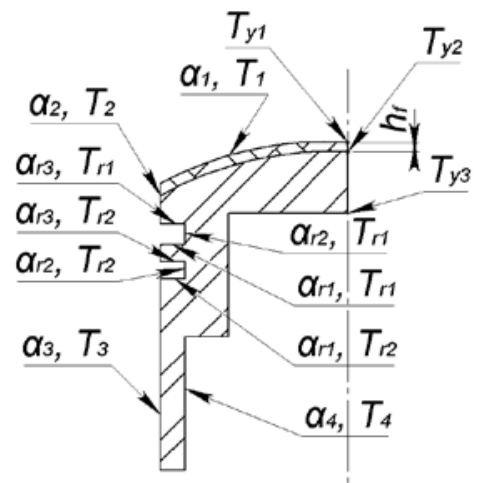

Fig. 1. Design scheme, boundary conditions and temperature control points.

The coating effect on the thermal state of the piston was modeled on the plan of full factorial experiment of the type $2^{2}$ [21]. As factors were used: the thickness $h_{f}$, and the coefficient of thermal conductivity $\lambda_{f}$ of the coating. The experiment plan given in Table 1 .

Table 1. Composite plan of experiment of second order for the two factors.

\begin{tabular}{|c|c|c|c|c|c|}
\hline \multirow{2}{*}{$\begin{array}{l}\text { Number of } \\
\text { experience }\end{array}$} & \multicolumn{2}{|c|}{$\begin{array}{c}\text { Factors in conventional } \\
\text { units }\end{array}$} & \multirow{2}{*}{$\begin{array}{l}\text { Number of } \\
\text { experience }\end{array}$} & \multicolumn{2}{|c|}{ Factors in conventional units } \\
\hline & $\mathrm{X}_{1}$ & $\mathbf{X}_{2}$ & & $\mathbf{X}_{1}$ & $\mathbf{X}_{2}$ \\
\hline 1 & -1 & -1 & 5 & 0 & 0 \\
\hline 2 & +1 & -1 & 6 & +1 & 0 \\
\hline 3 & -1 & +1 & 7 & -1 & 0 \\
\hline \multirow[t]{2}{*}{4} & +1 & +1 & 8 & 0 & +1 \\
\hline & & & 9 & 0 & -1 \\
\hline
\end{tabular}

The values of the factors and their variation levels are shown in Table 2. It is known that MAO-layers have a conductivity of $0.5-1.6 \mathrm{~W} /(\mathrm{m} \cdot \mathrm{K})[6,9]$. Therefore, the values of the coefficient of thermal conductivity of the MAO-layer for the experiment were chosen from the range $0.1-1.5 \mathrm{~W} /(\mathrm{m} \cdot \mathrm{K})$. The thickness of the MAO layer was also out of the achievable range: $50-300 \mu \mathrm{m}[5,7,8]$.

Table 2. Factors of the experiment.

\begin{tabular}{|c|c|c|c|c|c|}
\hline \multicolumn{2}{|c|}{ Factor } & \multicolumn{3}{c|}{ Level } & \multirow{2}{*}{$\begin{array}{c}\text { The range of } \\
\text { variation }\end{array}$} \\
\hline Property & Variable & $\mathbf{- 1}$ & $\mathbf{0}$ & $+\mathbf{1}$ & 0.7 \\
\hline $\begin{array}{c}\text { Coefficient of thermal conductivity } \\
\lambda_{f}, \mathrm{~W} / \mathrm{m} \cdot \mathrm{K}\end{array}$ & $\mathrm{X}_{1}$ & 0.1 & 0.8 & 1.5 & 125 \\
\hline $\begin{array}{c}\text { The thickness of the coating } h_{f}, \\
\mu \mathrm{m}\end{array}$ & $\mathrm{X}_{2}$ & 50 & 175 & 300 & 125 \\
\hline
\end{tabular}

Responses in all the numerical experiments were performed: the temperature of the piston top from the side of working chamber of the $T_{y l}$ and the side of the crankcase of the $T_{y 3}$, the temperature of the aluminum alloy under the coating $T_{y 2}$ (Fig.1). The results of the 
experiment were processed using the software DataFit [22] to obtain a regression equation. Selection criterion of the form of regression equations were parameter residual sum of squares, which shows the difference between data and a regression equation.

\section{The results of the research}

The experimental data showed that electrical conductivity of the material of the piston is related with the temperature according to the equation:

$$
\lambda_{A l}=0.154 T+43.448,
$$

where $\mathrm{T}$-temperature, $\mathrm{K}$.

The calculation in the simulation software "Albea" is allowed to obtain the parameters of the working cycle of the engine (Fig. 2). This data were used to determine the values of the boundary conditions for further calculations (Fig.1, Table 3).

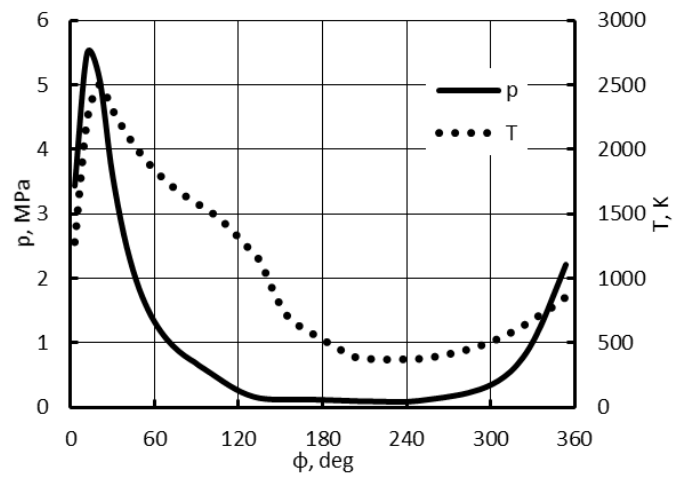

Fig. 2. Changing the parameters of the working cycle of the engine according to the crankshaft angle $\varphi$, where $\mathrm{p}$ is the indicated pressure, MPa $\mathrm{T}-$ temperature, $\mathrm{K}$.

Table 3. Boundary conditions

\begin{tabular}{|c|c|c|c|c|c|}
\hline Parameter & Value & Parameter & Value & Parameter & Value \\
\hline$\alpha_{1}$ & $592 \mathrm{~W} / \mathrm{m}^{2} \cdot \mathrm{K}$ & $T_{1}$ & $1413 \mathrm{~K}$ & $\alpha_{r 1}$ & $116009 \mathrm{~W} / \mathrm{m}^{2} \cdot \mathrm{K}$ \\
\hline$\alpha_{2}$ & $148 \mathrm{~W} / \mathrm{m}^{2} \cdot \mathrm{K}$ & $T_{2}$ & $1413 \mathrm{~K}$ & $\alpha_{r 2}$ & $1818 \mathrm{~W} / \mathrm{m}^{2} \cdot \mathrm{K}$ \\
\hline$\alpha_{3}$ & $1485 \mathrm{~W} / \mathrm{m}^{2} \cdot \mathrm{K}$ & $T_{3}$ & $473 \mathrm{~K}$ & $\alpha_{r 3}$ & $97 \mathrm{~W} / \mathrm{m}^{2} \cdot \mathrm{K}$ \\
\hline$\alpha_{4}$ & $174 \mathrm{~W} / \mathrm{m}^{2} \cdot \mathrm{K}$ & $T_{4}$ & $363 \mathrm{~K}$ & $T_{r l}$ & $573 \mathrm{~K}$ \\
\hline$T_{r 2}$ & $423 \mathrm{~K}$ & & & & \\
\hline
\end{tabular}

When modeling the thermal state of the piston in accordance with the two-factor experiment plan was carried out 9 calculations. As a result, an array of data was obtained in the form of temperature fields. In Fig. 3 shows the temperature fields in the Central cross section perpendicular to the axis of the gudgeon pin for piston without coating (Fig. 3, a) and of the piston with a coating thickness of $300 \mu \mathrm{m}$ and a coefficient of thermal conductivity $0.1 \mathrm{~W} / \mathrm{m} \cdot \mathrm{K}$ (Fig. 3, b). As a result of processing the obtained data were withdrawn following regression equation:

$$
T_{y l}=867,62+205,92 \cdot \ln \lambda_{f}-127,42 \cdot \ln h_{f}+25,54 \cdot \ln ^{2} \lambda_{f}+18,43 \cdot \ln ^{2} h_{f}-53,35 \cdot \ln \lambda_{f} \cdot \ln h_{f},
$$




$$
\begin{gathered}
T_{y 2}=607,59-52,03 \cdot \ln \lambda_{f}+18,75 \cdot \ln h_{f}-2,96 \cdot \ln ^{2} \lambda_{f}-2,85 \cdot \ln ^{2} h_{f}+11,89 \cdot \ln \lambda_{f} \cdot \ln h_{f}, \\
T_{y 3}=582,56-33,49 \cdot \ln \lambda_{f}+20,89 \cdot \ln h_{f}-4,33 \cdot \ln ^{2} \lambda_{f}-2,96 \cdot \ln ^{2} h_{f}+8,66 \cdot \ln \lambda_{f} \cdot \ln h_{f} .
\end{gathered}
$$

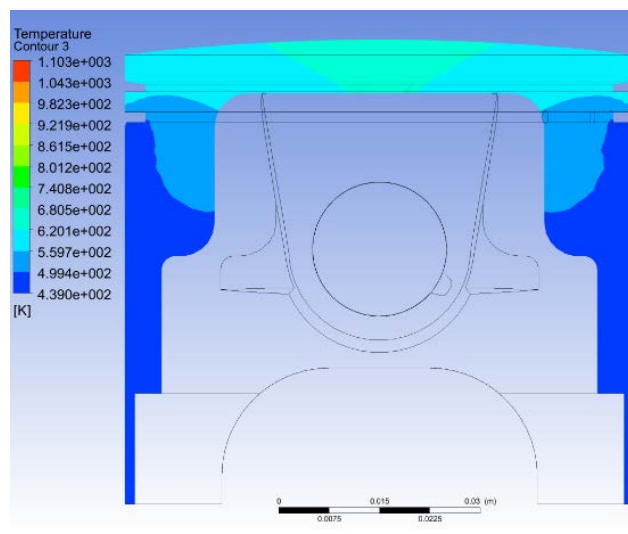

a

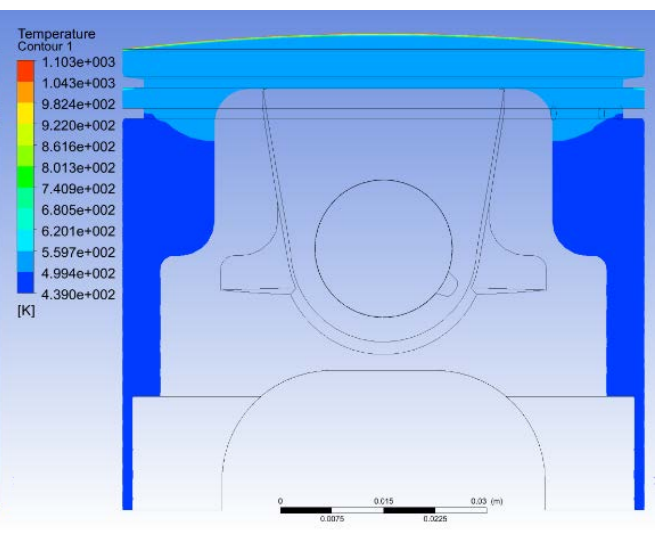

b

Fig. 3. The temperature field in the piston without coating (a) and piston cover (b) with thickness $h_{f}$ $=300 \mu \mathrm{m}$ and a coefficient of thermal conductivity $\lambda_{f}=0.1 \mathrm{~W} / \mathrm{m} \mathbf{X}$.

These equations describe the thermal state of the piston only in the presence of the coating on its top. Temperatures $T_{y 1}, T_{y 2}, T_{y 3}$ for piston without coating amounted to $636 \mathrm{~K}$, $635 \mathrm{~K}$ and $621 \mathrm{~K}$, respectively.

\section{Conclusion}

Analysis of the results obtained through simulations showed that the MAO coatings reduce the temperature of the aluminum alloy, of which the piston $\left(T_{y 2}, T_{y 3}\right)$, see formula $(4,5)$. However, the application of coatings with a thermal conductivity higher than $1 \mathrm{~W} / \mathrm{m} \cdot \mathrm{K}$, even when the coating thickness of 300 microns reduces the temperature of the material of the piston under the cover on $\sim 14 \ldots 15 \mathrm{~K}$ relative to the original piston. On the other hand, the thicker the coating and the lower the conductivity, the higher the temperature of the bottom of the piston $\left(T_{y l}\right)$, which can have a negative impact on the workflow engine. Thus, the thickness and conductivity of micro-arc oxide layer should be selected based on a compromise between reducing the temperature of the material of the piston and rise in temperature of the bottom of the piston. Based on the obtained regression equations it can be concluded that it is appropriate to apply MAO-layers with thermal conductivity of $0.3 \ldots 0.7 \mathrm{~W} / \mathrm{m} \cdot \mathrm{K}$ and thickness of $150 \ldots 300 \mu \mathrm{m}$. Under these conditions, we can expect a temperature reduction of the piston from the crankcase $27 . .55 \mathrm{~K}$.

This work was produced during the contract № 14.574.21.0161 from 26.09.2017 sponsored by the Ministry of Education and Science of the Russian Federation (a unique identifier of the work (project) RFMEFI57417X0161).

\section{References}

1. V. K. Afanasev, Piston's Silumin's (Poligraph, Kemerovo, 2005) 
2. H. Groe, Petrol and diesel engines (Za rulem, Moscow, 2013)

3. V. N. Lukanin, M. G. Shatrov, Internal combustion engines. Book 2. Dynamics and design (Hish School, Moscow, 2007)

4. M. D. Nikitin, Thermal and wear-resistant coatings of diesel engine parts (Mechanical engineering, Leningrad, 1977)

5. N. Yu. Dudareva, Nanotechnologies in power plant engineer-ing: scientific and educational course (Ufa State Aviation Technical University, Ufa, 2013)

6. M.M. Krishtal, P. V. Ivashin, A. V. Polunin, D. A. Pavlov, Vector of science TSU, 22, 169 (2012)

7. I. V. Suminov, A. V. Epelfeld, Microarc oxidation: theory, technology, equipment (Ekomet, Moscow, 2005)

8. I. V. Suminov, Plasma-electrolytic modification of the surface of metals and alloys (Technosfera, Moscow, 2011)

9. J. A. Curran, Thermal and mechanical properties of plasma electrolytic oxide coatings (Diss. University of Cambridge, 2006)

10. A. N. Batichev, News of Orlovsk St. Techn. University. Series Building. Transport, 1, 67 (2004)

11. D. A. Sibirkov, Reduction of heat stress of piston groups of marine diesel engines (Diss. Novosibirsk State. Acad. of Water Transp, 2004)

12. B. M. Nemenenok, V. A. Kalinichenko, M. A. Sadoha, V. I. Gutko, Casting and metallurgy, 34, 175 (2005)

13. A. N. Goc, S. A. Glinkin, Tractors and agricultural machines, 12, 34 (2016)

14. Information on http://dvs.ugatu.ac.ru

15. V. G. Gorbachev, S. A. Zagayko, N. V. Rudaya, B. P. Rudoy, Simulation system "Albeya" (core). User guide. Programmer's Guide: A Tutorial (Ufa State Aviation Technical University, Ufa, 1995)

16. D. V. Sivukhin, General course of physics: electricity (Fizmatlit, Moscow, 2004)

17. N. D. Chainov, Design of Internal Combustion Engines: Textbook for university students (EBS Lan, Moscow, 2011)

18. A. K. Kostin, Thermal stress of internal combustion engines (Mechanical engineering, Leningrad, 1979)

19. B. S. Stephanovsky, Testing of Internal Combustion Engines (Mechanical engineering, Moscow, 1972)

20. R.Z. Kavtaradze, Local Heat Transfer in Reciprocating Engines: Student handbook for universities (Moscow, 2007)

21. A. N. Gaydadin, S. A. Efremova, The use of computer facilities in the processing of an active experiment (Volgograd State Technical University, Volgograd, 2008)

22. Information on http://www.oakdaleengr.com/datafit.htm 